\title{
Notes
}

\section{High Thermal Stability and Rigid Rod of Novel Organosoluble Polyimides and Polyamides Based on Bulky and Noncoplanar Naphthalene-Biphenyldiamine}

\section{Der-Jang Liaw, ${ }^{*, \dagger}$ Feng-Chyuan Chang, ${ }^{\dagger}$ Man-kit Leung, ${ }^{\ddagger}$ Meng-Yen Chou, ${ }^{\ddagger}$ and Klaus Muellen ${ }^{\S}$}

Department of Chemical Engineering, National Taiwan University of Science and Technology, Taipei, Taiwan, ROC; Department of Chemistry, National Taiwan University, Taipei, Taiwan, ROC; and Max-Planck-Institute for Polymer Research, Ackermannweg 10, Mainz 55128, Germany

Received July 15, 2004

Revised Manuscript Received January 18, 2005

\section{Introduction}

Rigid-rod aromatic polyimides and polyamides constantly attract wider interest because of their unique mechanical, thermal, and morphological properties. ${ }^{1-7}$ Synthesis and processing of these materials are generally more difficult due to their limited solubility and infusibility. One of the successful approaches to increase solubility and processability of polymers is by the introduction of bulky lateral substituents, ${ }^{8-11}$ flexible alkyl side chains, ${ }^{12,13}$ unsymmetric, ${ }^{14}$ alicyclic, ${ }^{15,16}$ and kinked structure. ${ }^{17-20}$ To develop easily processable high-performance materials, modifications that increase the solubility while maintaining the rigid-rod character and the thermal stability are of particular interest.

Another approach employed to increase the solubility of rigid-rod polyimides and polyamides is by incorporation of the nonlinear moieties such as a bulky noncoplanar group in the polymer backbone. In a previous study, ${ }^{21-28}$ the solubility, thermal and thermooxidative stability, optical properties, transition, and relaxation behaviors of organosoluble aromatic polyimide could be improved by addition of 2,2 -disubstituted groups like methyl, cyano, trifluoromethyl groups, methyl-substituted phenyl groups, halogens, methacrylate, sulfonic acid, trifluoromethylphenyl groups, and biphenyl groups substituted at different positions to main-chain 4,4'diaminobiphenyls. The 2,2'-disubstituted biphenylylene moiety could be considered as a rodlike structure and adopts a noncoplanar conformation in the presence of methyl substitution at the $2,2^{\prime}$-position. The substitution at the 2- and 2'-positions of the biphenyl moiety forces the rings out of the plane into adopting a noncoplanar conformation. ${ }^{23,27,28}$ Naphthalene structure is bulky and rigid which also has high heat resistance..$^{29,30}$ Incorporation of the naphthalene group at the $2,2^{\prime}$-position of

\footnotetext{
National Taiwan University of Science and Technology.

$\$$ National Taiwan University.

$\S$ Max-Planck-Institute for Polymer Research.

* Corresponding author: Fax 886-2-23781441 or 886-2-27376644; e-mail liaw@ch.ntust.edu.tw or liaw8484@yahoo.com.tw.
}

biphenylylene may disrupt the crystal packing, reducing intermolecular interactions and enhancing solubility of the polyimide and polyamide.

In the present paper, we will report the synthesis of a new naphthalene-substituted monomer, 2,2 '-dinaphthylbiphenyl-4,4'-diamine, and its use in the preparation of soluble polyimides and polyamides by the reaction of the diamine with commercial dianhydrides and dicarboxylic acids. The solubility, tensile properties, thermal properties, electrochemical stability, and dielectric constants of the obtained polyimides and polyamides are also investigated.

\section{Experimental Section}

Materials. Reagent-grade aromatic tetracarboxylic dianhydrides such as $4,4^{\prime}$-hexafluoroisopropylidenediphathalic anhydride (6FDA) (I-1), 4,4'-sulfonyldiphthalic anhydride (DSDA) (I-2), and 3,3',4,4'-benzophenone-tetracarboxylic dianhydride (BTDA) (I-3) and aromatic dicarboxylic acids such as isophthalic acid (II-1), 5-tert-butylisophthalic acid (II-2), 4,4'sulfonyldibenzoic acid (II-3), and 4,4'-hexafluoroisopropylidenedibenzoic acid (II-4) were used after purification by crystallization. Reagent-grade calcium chloride was dried under vacuum at $180^{\circ} \mathrm{C}$ before use. $N$-Methyl-2-pyrrolidinone (NMP), $N, N$-dimethylacetamide (DMAc), $N, N$-dimethylformamide (DMF), pyridine, dimethyl sulfoxide (DMSO), triphenyl phosphite (TPP), $\gamma$-butyrolactone, and cyclohexanone were purified by distillation under reduced pressure over calcium hydride and stored over $4 \AA$ molecular sieves.

Measurements. IR spectra of synthesized monomers and polymers ( $\mathrm{KBr}$ disks) were recorded in the range 4000-500 $\mathrm{cm}^{-1}$ on a Jasco IR-700 spectrometer. Melting point was recorded on a MEL-TEMP II. The inherent viscosities of all polymers were measured using a Ubbelohde viscometer. Nuclear magnetic resonance (NMR) spectra were recorded on a Varian VXR400S $\left({ }^{1} \mathrm{H}\right.$ at $399.96 \mathrm{MHz}$ and ${ }^{13} \mathrm{C}$ at $\left.100.58 \mathrm{MHz}\right)$. Mass spectra (MS) were recorded by a Joel JMS-HX 110. Elemental analysis (EA) was recorded by a Heraeus CHN-O Rapid. Thermogravimetric data were obtained on a TA 5100 thermal analysis system under nitrogen flowing conditions nitrogen $\left(60 \mathrm{~cm}^{3} \mathrm{~min}^{-1}\right)$ at a heating rate of $10{ }^{\circ} \mathrm{C} \mathrm{min}-1$. Differential scanning calorimetric analysis was performed on a differential scanning calorimeter (TA Instruments TA-2010) at a heating rate of $10{ }^{\circ} \mathrm{C} \mathrm{min}^{-1}$. Tensile properties were determined from stress - strain curves obtained with a Orientec Tensilon with a load cell of $10 \mathrm{~kg}$. A gauge of $2 \mathrm{~cm}$ and a strain rate of $2 \mathrm{~cm} \mathrm{~min}{ }^{-1}$ were used for this study. Measurements were performed at room temperature with film specimens of dimensions $0.4 \mathrm{~cm}$ wide, $5 \mathrm{~cm}$ long, and $0.1 \mathrm{~mm}$ thick. Dielectric constants of polyimide thin film were measured by the parallel-plate capacitor method using a dielectric analyzer (TA Instruments DEA 2970) at a frequency of $1 \mathrm{kHz}$. Gold electrodes were vacuum-deposited on both surfaces of dried films, and measurements were made at $25{ }^{\circ} \mathrm{C}$ under a $\mathrm{N}_{2}$ atmosphere. Electrochemical stability was measured by a cyclic voltammetry instrument BAS CV-27 voltammograph. The method is $(0-1.5 \mathrm{~V}, 100 \mathrm{mV} / \mathrm{s})$ in DMF using $\mathrm{Bu}_{4} \mathrm{NClO}_{4}$ $(0.1 \mathrm{M})$ as the supporting electrolyte. The signals were obtained on a platinum working electrode, with a Pt wire as the counter electrode and a $\mathrm{Ag} / \mathrm{AgCl}$ (saturated) electrode as the reference electrode. 
Scheme 1. Synthesis of 2,2'-Dinaphthylbiphenyl-4,4'-diamine (4)

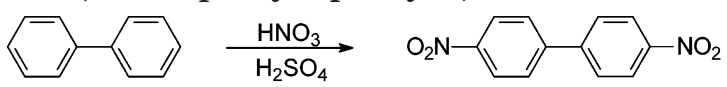

(1)

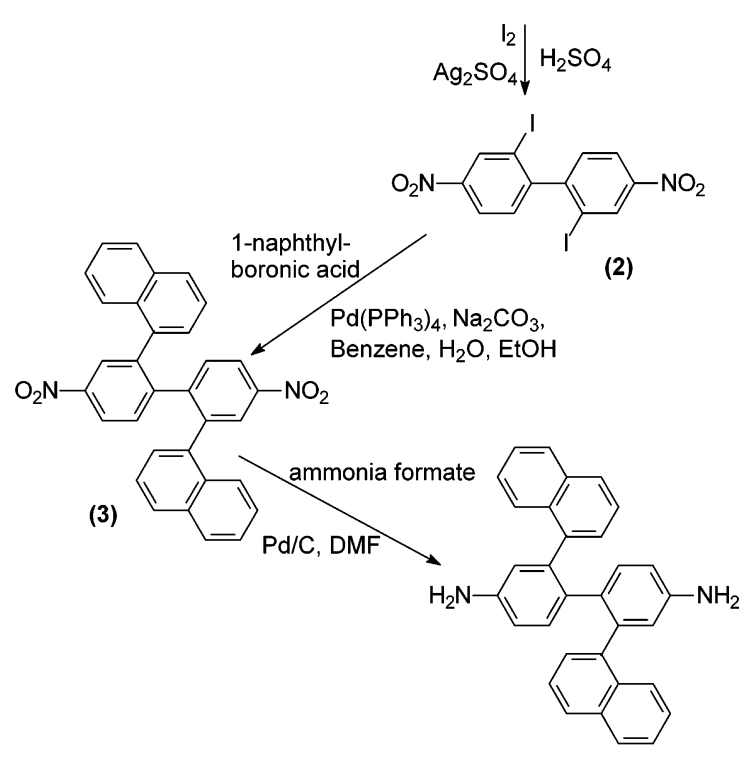

(4)

Monomer Syntheses (Scheme 1). Synthesis of 4,4'-Dinitrobiphenyl (1). A concentrated $\mathrm{HNO}_{3}(70 \%, 4.4 \mathrm{~mL})$ was added to concentrated $\mathrm{H}_{2} \mathrm{SO}_{4}(98 \%, 5.2 \mathrm{~mL})$ with stirring at 0 ${ }^{\circ} \mathrm{C}$ for $5 \mathrm{~min}$. Afterward, a solution of biphenyl [3 g, $19.5 \mathrm{mmol}$, $2 \mathrm{M}$ in nitromethane $\left(\mathrm{MeNO}_{2}\right)$ ] was added dropwise with stirring at $0{ }^{\circ} \mathrm{C}$. After the addition was completed, the solution was further stirred for $1 \mathrm{~h}$ at $0{ }^{\circ} \mathrm{C}$ and at for $2 \mathrm{~h} 35^{\circ} \mathrm{C}$. The solution was poured into ice-water, and the solid precipitate was collected, washed with water, and recrystallized from methanol and toluene to give $\mathbf{1}(0.825 \mathrm{~g}, 17 \%)$ as light yellow solid. ${ }^{1} \mathrm{H}$ NMR $\left(400 \mathrm{MHz}, \mathrm{CDCl}_{3}\right): \delta 8.34(\mathrm{~d}, J=8.6 \mathrm{~Hz}, 4 \mathrm{H})$, $7.77(\mathrm{~d}, J=8.6 \mathrm{~Hz}, 4 \mathrm{H}) .{ }^{13} \mathrm{C}$ NMR $\left(100 \mathrm{MHz}, \mathrm{CDCl}_{3}\right): \delta 148.06$, 144.97, 128.32, 124.37. HRMS-FAB m/z calcd for $\mathrm{C}_{12} \mathrm{H}_{8} \mathrm{~N}_{2} \mathrm{O}_{4}$ 244.0484; found 244.0497.

Synthesis of 2,2'-Diiodo-4,4'-dinitrobiphenyl (2). A solution of 4,4'-dinitrobiphenyl (10 g, $41 \mathrm{mmol}$ ), $\mathrm{Ag}_{2} \mathrm{SO}_{4}$ (34.3 g, 110 $\mathrm{mmol}$ ), and $\mathrm{I}_{2}(31.2 \mathrm{~g}, 123 \mathrm{mmol})$ in $\mathrm{H}_{2} \mathrm{SO}_{4}(98 \%, 164 \mathrm{~mL})$ was heated at $120{ }^{\circ} \mathrm{C}$ for $20-48 \mathrm{~h}$. Since the reactivities of $\mathrm{Ag}_{2} \mathrm{SO}_{4}$ are different from batch of batch, the reaction was monitored by using ${ }^{1} \mathrm{H}$ NMR. When the conversion reached $75 \%$ or above, the solution was poured into $2000 \mathrm{~mL}$ of ice-water, and the solid precipitate was collected, washed with water, and recrystallized from ethyl acetate to give $2(13.2 \mathrm{~g}, 65 \%)$ as a light yellow solid; mp $148-149{ }^{\circ} \mathrm{C}$. ${ }^{1} \mathrm{H}$ NMR $(400 \mathrm{MHz}$, $\left.\mathrm{CDCl}_{3}\right): \delta 8.75(\mathrm{~d}, J=2.2 \mathrm{~Hz}, 2 \mathrm{H}), 8.30(\mathrm{dd}, J=8.4,2.2 \mathrm{~Hz}$, $2 \mathrm{H}), 7.37(\mathrm{~d}, J=2.2 \mathrm{~Hz}, 2 \mathrm{H}) .{ }^{13} \mathrm{C} \mathrm{NMR}\left(100 \mathrm{MHz} \mathrm{CDCl}_{3}\right): \delta$ 152.96, 147.60, 133.91, 129.84, 123.27, 97.91. HRMS-FAB m/z calcd for $\mathrm{C}_{12} \mathrm{H}_{6} \mathrm{O}_{4} \mathrm{~N}_{2} \mathrm{I}_{2}$ 495.8417; found 495.8410 .

Synthesis of 2,2'-Dinaphthyl-4,4'-dinitrobiphenyl (3). A solution of 2,2'-diiodo-4,4'-dinitrobiphenyl (10.0 g, $20 \mathrm{mmol}$ ), 1-naphthylboronic acid $(20.8 \mathrm{~g}, 121 \mathrm{mmol}), \mathrm{Pd}\left(\mathrm{PPh}_{3}\right)_{4}(0.46 \mathrm{~g}$, $0.4 \mathrm{mmol})$, and $\mathrm{Na}_{2} \mathrm{CO}_{3}(6.6 \mathrm{~g}, 62 \mathrm{mmol})$ in benzene $(30 \mathrm{~mL})$, $\mathrm{H}_{2} \mathrm{O}(15 \mathrm{~mL})$, and ethanol $(5 \mathrm{~mL})$ was heated at $80{ }^{\circ} \mathrm{C}$ under a $\mathrm{N}_{2}$ atmosphere for $4 \mathrm{~h}$. When the reaction was completed, the solution was quenched with $\mathrm{H}_{2} \mathrm{O}$ and extracted with $\mathrm{CHCl}_{3}$. The organic layer was collected, dried over anhydrous $\mathrm{MgSO}_{4}$, and concentrated under vacuum to give a glassy product which was purified by column chromatography on silica gel (hexane:ethyl acetate $=1: 6)$ to give $\mathbf{3}(8.7 \mathrm{~g}, 87 \%)$ as a yellow solid; mp $203-204{ }^{\circ} \mathrm{C} .{ }^{1} \mathrm{H}$ NMR $\left(400 \mathrm{MHz}, \mathrm{CDCl}_{3}\right)$ : $\delta 8.32-5.83(\mathrm{~m}, 20 \mathrm{H}) .{ }^{13} \mathrm{C} \mathrm{NMR}\left(100 \mathrm{MHz}, \mathrm{CDCl}_{3}\right): \delta 146.87$, $145.89,140.38,135.14,133.61,132.64,128.67,128.25,126.85$, $126.65,126.15,125.83,125.03,124.41,121.77$. Note that restricted rotation around $\mathrm{C}-\mathrm{C}$ bonds of the naphthylbiphenyl groups leads to coalesced aromatic signals. We have successfully obtained structural evidence from X-ray crystallography of 4,4'-dinitro-2,2'-dinaphthylbiphenyl. HRMS-FAB $\mathrm{m} / \mathrm{z}$ calcd for $\mathrm{C}_{32} \mathrm{H}_{20} \mathrm{O}_{4} \mathrm{~N}_{2}$ 496.1423; found 496.1419. Elemental analysis: Calcd for $\mathrm{C}_{32} \mathrm{H}_{20} \mathrm{O}_{4} \mathrm{~N}_{2}$ : C, 77.41; H, 4.06; N, 5.64; Found: C, 77.36; H, 3.70; N, 5.44.

Synthesis of 2,2'-Dinaphthylbiphenyl-4,4'-diamine (4). A solution of ammonia formate $(0.83 \mathrm{~g}, 7.8 \mathrm{mmol}), 10 \% \mathrm{Pd} / \mathrm{C}$ $(0.18 \mathrm{~g}, 2.8 \mathrm{mmol})$, and $2,2^{\prime}$-dinaphthyl-4,4'-dinitrobiphenyl (0.65 g, $1.3 \mathrm{mmol})$ in DMF $(2 \mathrm{~mL})$ was heated at $80{ }^{\circ} \mathrm{C}$ for $3 \mathrm{~h}$. After then, water was added to quench the reaction. The crude product was extracted with ethyl acetate several times. The organic layer was collected, dried over anhydrous $\mathrm{MgSO}_{4}$, and concentrated under vacuum to give a glassy product which was purified by column chromatography on silica gel (hexane:ethyl acetate $=1: 3)$ and recrystallized from methanol to give $4(0.45$ g, $73 \%)$ as a light pink solid. ${ }^{1} \mathrm{H}$ NMR $\left(400 \mathrm{MHz}, \mathrm{CD}_{3} \mathrm{COCD}_{3}\right)$ : $\delta 7.81-6.33(\mathrm{~m}, 20 \mathrm{H}), 4.44(\mathrm{~s}, 4 \mathrm{H}),{ }^{13} \mathrm{C}$ NMR $(100 \mathrm{MHz}$, $\left.\mathrm{CD}_{3} \mathrm{COCD}_{3}\right): \delta 146.72,141.04,140.40,134.60,133.70,131.20$, $128.56,127.77,127.36,127.30,125.91,125.86,125.33,118.04$, $117.87,113.99$. HRMS-FAB $m / z$ calcd for $\mathrm{C}_{32} \mathrm{H}_{24} \mathrm{~N}_{2} 436.1940$; found 436.1935. Elemental analysis: Calcd for $\mathrm{C}_{32} \mathrm{H}_{24} \mathrm{~N}_{2}$ : C, 88.04; H, 5.54; N, 6.42. Found: C, 87.65; H, 5.56; N, 6.34.

Polymerization. Preparation of Polyimide (PI-1 and PI3). A three-necked flask was charged with $0.4366 \mathrm{~g}(1 \mathrm{mmol})$ of naphthalenediamine (4) and $5 \mathrm{~mL}$ of DMAc. The solution was stirred under a nitrogen atmosphere until the diamine dissolved completely, and then $0.4442 \mathrm{~g}(1 \mathrm{mmol})$ of dianhydride (I-1) was added to the reaction mixture slowly. The mixture was stirred at ambient temperature for $2-4 \mathrm{~h}$ under a nitrogen atmosphere to form poly(amic acid). The poly(amic acid) was diluted with extra DMAc, and a mixture of equimolar of acetic anhydride and pyridine was added to the poly(amic acid) solution with stirring at ambient temperature for $1 \mathrm{~h}$, and then the mixture was heated to $100{ }^{\circ} \mathrm{C}$ and maintained at $100{ }^{\circ} \mathrm{C}$ for $3 \mathrm{~h}$. After cooling, the viscous polymer solution was poured into methanol. The precipitate was filtered, washed thoroughly with methanol and hot water, and dried at $100{ }^{\circ} \mathrm{C}$ under vacuum. The inherent viscosity of the PI-1 in DMAc was $0.81 \mathrm{dL} \mathrm{g}^{-1}$, measured at a concentration of $0.5 \mathrm{~g}$ $\mathrm{dL}^{-1}$ at $30^{\circ} \mathrm{C}$. Elemental analysis: Calcd for $\left(\mathrm{C}_{51} \mathrm{H}_{26} \mathrm{O}_{4} \mathrm{~N}_{2} \mathrm{~F}_{6}\right)_{n}$ : C, $72.51 \%$; H, 3.10\%; N, 3. 32\%. Found: C, 71.56\%; H, 3.49\%; N, 2.96\%. Since PI-3 synthesized by the chemical imidization method was precipitated during imidization, PI-3 was obtained by thermal imidization. The poly(amic acid) solution was also carried out by an identical method. A poly(amic acid) film was cast from the solution into a glass culture dish and heated (8 $\mathrm{h}$ at $80{ }^{\circ} \mathrm{C}, 2 \mathrm{~h}$ at $150{ }^{\circ} \mathrm{C}, 2 \mathrm{~h}$ at $200{ }^{\circ} \mathrm{C}, 2 \mathrm{~h}$ at $250{ }^{\circ} \mathrm{C}$, and 2 $\mathrm{h}$ at $300^{\circ} \mathrm{C}$ ) under vacuum to convert the poly(amic acid) into polyimide film. Elemental analysis: Calcd for $\left(\mathrm{C}_{49} \mathrm{H}_{26} \mathrm{O}_{5} \mathrm{~N}_{2}\right)_{n}$ : C, 81.43\%; H, 4.32\%; N, 3.86\%. Found: C, 79.84\%; H, 3.97\%; $\mathrm{N}, 3.21 \%$.

Preparation of Polyamide (PA-1). A mixture of $0.2183 \mathrm{~g}(0.5$ mmol) of diamine (4), $0.083 \mathrm{~g}(0.5 \mathrm{mmol})$ of isophthalic acid (II-1), $0.5 \mathrm{~mL}$ of triphenyl phosphite (TPP), $0.5 \mathrm{~mL}$ of pyridine, $3.0 \mathrm{~mL}$ of $N$-methyl-2-pyrrolidone (NMP), and $0.30 \mathrm{~g}$ of calcium chloride was heated with stirring at $100{ }^{\circ} \mathrm{C}$ for $3 \mathrm{~h}$. After cooling, the reaction mixture was poured into a large quantity of methanol with constant stirring, and the polymer was precipitated. The precipitate was filtered and washed thoroughly with methanol and hot water and dried at $100{ }^{\circ} \mathrm{C}$ under vacuum. Various polyamides (PA-2-PA-4) were prepared by using a similar procedure. The inherent viscosity of the polyamide (PA-1) in DMAc was $0.73 \mathrm{dL} \mathrm{g}^{-1}$, measured at a concentration $0.5 \mathrm{~g} \mathrm{dL}^{-1}$ at $30^{\circ} \mathrm{C}$. Elemental analysis: Calcd for $\left(\mathrm{C}_{40} \mathrm{H}_{26} \mathrm{O}_{2} \mathrm{~N}_{2}\right)_{n}$ : C, 84.78\%; H, 4.62\%; N, 4.94\%. Found: $\mathrm{C}$, $79.69 \%$; H, $4.96 \%$; N, $4.27 \%$.

\section{Results and Discussion}

Monomer Synthesis. The 2,2'-dinaphthylbiphenyl$4,4^{\prime}$-diamine (4) was prepared according to Scheme 1. First, the biphenyl was nitrated to the $4,4^{\prime}$-dinitrobiphenyl (1) compound with nitric acid and sulfuric acid 
Scheme 2. Synthesis of Various Polyimides (PI-1-PI-3)

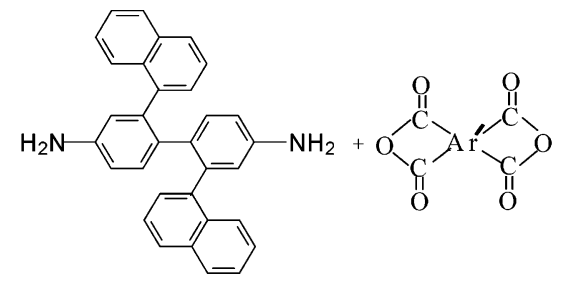

(4)

I-1 $\sim$ I-3

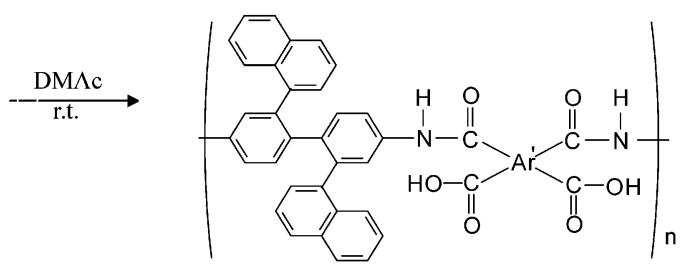

PAA-1 PAA-3

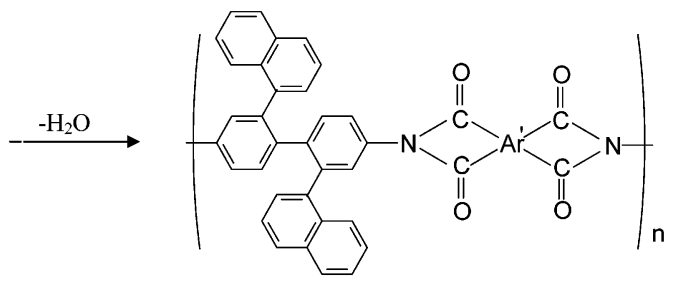

PI-1 PI-3

Ar':

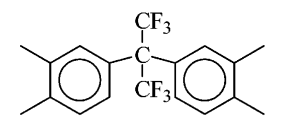

(1)

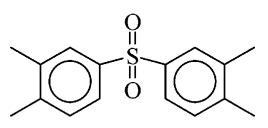

(2)

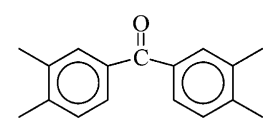

(3) at $0{ }^{\circ} \mathrm{C}$. The dinitro compound (1) was then iodinated using Marvel's reaction condition ${ }^{31}$ which is the electrophilic aromatic substitution of iodine cation to give the 2,2'-diiodo-4,4'-dinitrobiphenyl (2) compound. Further, the diiodo-dinitro compound (2) treated with 1-naphthylboronic acid by the Susuki coupling reaction afforded the 2,2'-dinaphthyl-4,4'-dinitrobiphenyl (3). Finally, the nitrobiphenyl group was converted to an amine group with ammonium formate, $10 \% \mathrm{Pd} / \mathrm{C}$, and $\mathrm{DMF}$ solution at $80{ }^{\circ} \mathrm{C}$. All the structures of these compounds were confirmed by NMR, MS, and EA. The results of these compounds were in agreement with their respective structure.

Preparation of Polyimides. Polyimides were prepared by the conventional two-step polymerization method, as outlined in Scheme 2, involving ring-opening polyaddition forming poly(amic acid) and subsequent chemical or thermal imidization. Reaction of dianhydride with diamine at ambient temperature gave viscous poly(amic acid) solution. The chemical imidization of poly(amic acid)s proceeded with a dehydrating agent such as a mixture of acetic anhydride and pyridine. The dehydration was effective and afforded polyimides. Before addition of dehydrating agents, extra DMAc was added to the poly(amic acid) solutions to prevent gelation. However, polyimide PI-3 synthesized by the chemical imidization method was precipitated during imidization. The poly(amic acid) solution was cast into glass plate and heated to $300{ }^{\circ} \mathrm{C}$ gradually under vacuum. The polyimide was formed through cyclodehydration by
Scheme 3. Synthesis of Various Polyamides (PA-1-PA-4)

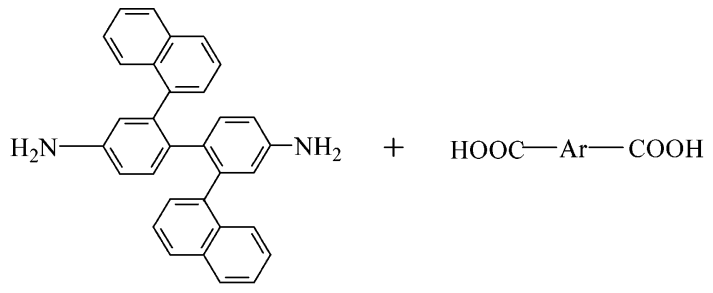

(4)

II-1 II-4

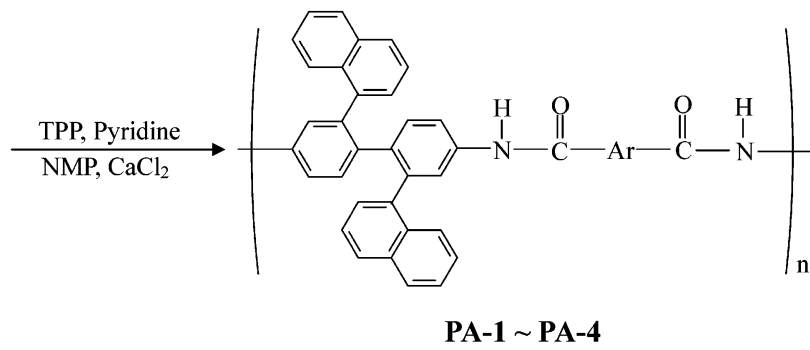

Ar :

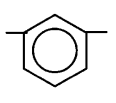

(1)

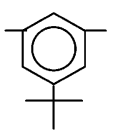

(2)

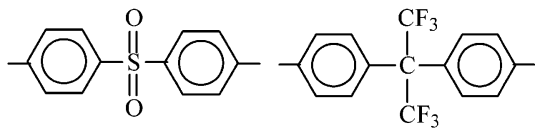

(3)

(4) removing solvent slowly. The polyimides obtained by chemical method had inherent viscosities between 0.81 and $0.85 \mathrm{dL} \mathrm{g}^{-1}$ in DMAc. The molecular weights of polyimides were sufficient for casting tough and flexible films. The IR spectra of polymers confirmed the formation of polyimides. The IR spectrum of polyimide, PI-1 obtained by the chemical imidization method showed characteristic bands at 1788 and $1725 \mathrm{~cm}^{-1}$ due to the asymmetric and symmetric stretches of imide carbonyl groups, respectively, and a band at $1388 \mathrm{~cm}^{-1}$ due to $\mathrm{C}-\mathrm{N}$ stretching which confirmed the formation of imide structure.

Preparation of Polyamides. The novel polyamides PA-1-PA-4 were prepared by direct polycondensation of the diamine $\mathbf{4}$ with a series of aromatic dicarboxylic acids in NMP using triphenyl phosphite (TPP) and pyridine as condensing agents (Scheme 3). All the polycondensations readily proceeded in homogeneous solution. Tough and stringy precipitates formed when the viscous polyamide solution were trickled into stirring methanol. All the polymers were obtained in quantitative yields with moderate to high inherent viscosities of $0.72-0.86 \mathrm{dL} \mathrm{g}^{-1}$ in DMAc, as listed in Table 1. The molecular weights of polyamides were sufficient for casting tough and flexible films. The formation of polyamides was confirmed by IR spectroscopy. The IR spectra of polyamides exhibited characteristic bands around $3300 \mathrm{~cm}^{-1}$ due to amide $\mathrm{N}-\mathrm{H}$ stretching and around $1660 \mathrm{~cm}^{-1}$ due to amide $\mathrm{C}=\mathrm{O}$ stretching confirmed the formation of amide structure.

Polymer Properties. Table 1 summarizes the solubility and quality of the films of polyimides and polyamides. These polymers exhibited a good solubility in a variety of solvents such as $N$-methyl-2-pyrrolidinone, $N, N$-dimethylacetamide, $N, N$-dimethylformamide, pyridine, tetrahydrofuran, dimethyl sulfoxide, $\gamma$-butyrolactone, and cyclohexanone at ambient temperature or 
Table 1. Viscosity, Solubility and Film Quality of Various Polyimides and Polyamides

\begin{tabular}{|c|c|c|c|c|c|c|c|c|c|c|}
\hline \multirow[b]{2}{*}{ polymer code } & \multirow[b]{2}{*}{$\eta_{\operatorname{inh}^{a}}\left(\mathrm{dL} \mathrm{g}^{-1}\right)$} & \multicolumn{8}{|c|}{ solubility $^{c}$} & \multirow[b]{2}{*}{ film quality } \\
\hline & & NMP & DMAc & $\mathrm{DMF}$ & DMSO & pyridine & THF & $\gamma$-butyrolactone & cyclohexanone & \\
\hline PI-1 & 0.81 & ++ & ++ & ++ & ++ & ++ & ++ & ++ & ++ & flexible \\
\hline PI-2 & 0.85 & ++ & ++ & ++ & +- & ++ & + & + & + & flexible \\
\hline PI-3 & $b$ & +- & - & - & - & - & - & - & - & flexible \\
\hline Ref 1 & N/A & ++ & +- & +- & +- & +- & +- & - & +- & $\mathrm{N} / \mathrm{A}^{d}$ \\
\hline PA-1 & 0.73 & ++ & ++ & ++ & ++ & ++ & +- & - & ++ & flexible \\
\hline PA-2 & 0.86 & ++ & ++ & ++ & + & ++ & + & ++ & ++ & flexible \\
\hline PA-3 & 0.72 & ++ & ++ & ++ & ++ & ++ & - & ++ & + & flexible \\
\hline PA-4 & 0.76 & ++ & ++ & ++ & ++ & ++ & + & ++ & ++ & flexible \\
\hline Ref 2 & N/A & ++ & ++ & ++ & ++ & + & - & + & - & N/A \\
\hline
\end{tabular}

${ }^{a}$ Measured in DMAc at a concentration of $0.5 \mathrm{~g} \mathrm{dL}-1$ at $30{ }^{\circ} \mathrm{C} .{ }^{b}$ Polymer was obtained by thermal imidization and insoluble in DMAc. ${ }^{c}$ Solubility: ++ , soluble at room temperature; + , soluble on heating at $70{ }^{\circ} \mathrm{C} ;+-$, partially soluble on heating at $70{ }^{\circ} \mathrm{C} ;-$, insoluble on heating at $70^{\circ} \mathrm{C}$. Abbreviations: NMP, $N$-methyl-2-pyrrolidinone; DMAc, $N, N$ - dimethylacetamide; DMF, $N, N$-dimethylformamide; DMSO, dimethyl sulfoxide; THF, tetrahydrofuran. ${ }^{d} \mathrm{~N} / \mathrm{A}=$ not available.<smiles></smiles>

Figure 1. Structure of Ref 1.

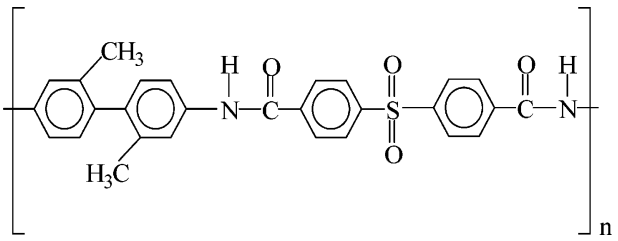

Figure 2. Structure of Ref 2.

Table 2. Thermal Properties of Various Polyimides and Polyamides

\begin{tabular}{cccccc}
\hline $\begin{array}{c}\text { polymer } \\
\text { code }\end{array}$ & $T_{\mathrm{g}}{ }^{a}\left({ }^{\circ} \mathrm{C}\right)$ & $\begin{array}{c}T_{\mathrm{d}}{ }^{10}\left({ }^{\circ} \mathrm{C}\right)^{b} \\
\text { in } \mathrm{N}_{2}\end{array}$ & $\begin{array}{c}\text { polymer } \\
\text { code }\end{array}$ & $T_{\mathrm{g}}{ }^{a}\left({ }^{\circ} \mathrm{C}\right)$ & $\begin{array}{c}T_{\mathrm{d}}{ }^{10}\left({ }^{\circ} \mathrm{C}\right)^{b} \\
\text { in } \mathrm{N}_{2}\end{array}$ \\
\hline PI-1 & 311 & 583 & PA-2 & 298 & 511 \\
PI-2 & 288 & 533 & PA-3 & 318 & 512 \\
PI-3 & 309 & 580 & PA-4 & 303 & 505 \\
PA-1 & 302 & 520 & & &
\end{tabular}

${ }^{a}$ Glass transition temperature $\left(T_{\mathrm{g}}\right)$ was measured by DSC at a heating rate of $10{ }^{\circ} \mathrm{C} \mathrm{min}{ }^{-1} .{ }^{b}$ Temperature at which $10 \%$ weight loss occurred, as recorded on TGA at a heating rate of $10^{\circ} \mathrm{C} \mathrm{min}-1$.

upon heating at $70^{\circ} \mathrm{C}$. The good solubility was governed by the structural modification through the incorporation of the bulky and noncoplanar naphthalene groups in the polymer backbone, which renders the polymer noncoplanar and also decreases interchain interactions. Comparing PI-1 and PA-3 with Figure 1 (Ref 1) and Figure 2 (Ref 2), respectively, polymers Ref 1 and Ref 2 containing methyl substitution with smaller free volume than naphthalene were prepared with the corresponding dianhydride and dicarboxylic acid. It was observed that polyimide Ref $\mathbf{1}$ and polyamide Ref $\mathbf{2}$ showed poorer solubility than its analogous polymers PI-2 and PA-3. It may be attributed to the presence of the naphthalene group in the polymer backbone.

The thermal properties of the polyimides were evaluated by differential scanning calorimetry (DSC) and thermogravimetric analysis (TGA). The results are summarized in Table 2.

The glass transition temperatures $\left(T_{\mathrm{g}}\right)$ of the polymers were found to be in the range of $288-318^{\circ} \mathrm{C}$. The $10 \%$ weight loss temperatures $\left(T_{\mathrm{d}}{ }^{10}\right)$ of polymers in the atmosphere of nitrogen at a heating rate of $10^{\circ} \mathrm{C} \mathrm{min}-1$ were obtained by thermal gravimetric analysis (TGA).

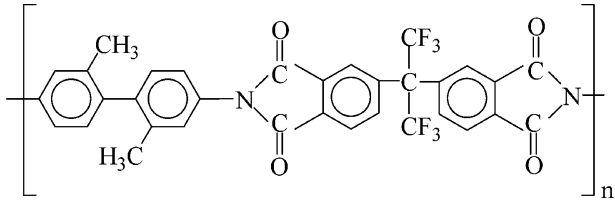

Figure 3. Structure of Ref 3.

Table 3. Mechanical Properties of Various Polyimides and Polyamides

\begin{tabular}{cccc}
\hline $\begin{array}{c}\text { polymer } \\
\text { code }\end{array}$ & $\begin{array}{c}\text { tensile } \\
\text { strength }(\mathrm{MPa})\end{array}$ & $\begin{array}{c}\text { elongation at } \\
\text { break }(\%)\end{array}$ & $\begin{array}{c}\text { tensile modulus } \\
(\mathrm{GPa})\end{array}$ \\
\hline PI-1 & 99 & 8 & 2.2 \\
PI-2 & 105 & 6 & 2.2 \\
PI-3 & 128 & 8 & 2.6 \\
PA-1 & 84 & 6 & 2.2 \\
PA-2 & 108 & 10 & 2.0 \\
PA-3 & 97 & 7 & 2.3 \\
PA-4 & 94 & 10 & 2.1
\end{tabular}

The temperature for $10 \%$ weight loss were in the range of $533-583$ and $505-520{ }^{\circ} \mathrm{C}$ for polyimides and polyamides, respectively. The $T_{\mathrm{g}}$ and $T_{\mathrm{d}}{ }^{10}$ of the polyimide PI-1 and polyamide PA-3 were compared with the corresponding reference polymers in Figure 3(Ref 3) (polyimide) and in Figure 2 (Ref 2) (polyamide), respectively. Polyimide PI-1 and polyamide PA-3 exhibited lower $T_{\mathrm{g}}$ and higher $T_{\mathrm{d}}{ }^{10}$ than the reference polymers Ref $3\left(T_{\mathrm{g}}=325^{\circ} \mathrm{C}\right.$ and $\left.T_{\mathrm{d}}{ }^{10}=523^{\circ} \mathrm{C}\right)$ and $\operatorname{Ref} \mathbf{2}\left(T_{\mathrm{g}}=\right.$ $320{ }^{\circ} \mathrm{C}$ and $\left.T_{\mathrm{d}}{ }^{10}=439{ }^{\circ} \mathrm{C}\right)$, respectively. The incorporation with naphthalene group at the $2,2^{\prime}$-position on the biphenyldiamine increase the size and sharp anisotropy of the 2,2'-disubstituted group of the diamine and affect the molecular packing. ${ }^{21-23}$ This makes the motion related to the $\beta$-relaxation evolvement from a noncooperative process to a cooperative one, and the $\alpha$-relaxation temperature which is the glass transition temperature $\left(T_{\mathrm{g}}\right)$ is correspondingly decreased. ${ }^{21-23}$ Therefore, the incorporation of the bulky naphthalene group could improve the processing characteristics of these relatively intractable polymers. In addition, the high $T_{\mathrm{d}}{ }^{10}$ of these novel polyimides and polyamides is also due to the presence of a rigid naphthalene group in the polymer backbone, which enhances the thermal stability of these polymers.

Table 3 lists the mechanical properties of the films of polyimide and polyamide. The flexible films were obtained by casting polymer solution in DMAc. They had a tensile strength in the range of $84-128 \mathrm{MPa}$, an elongation at break in the range of $6-10 \%$, and a tensile modulus in the range of 2.0-2.6 GPa. It was observed that polymer PI-3 derived from thermal cyclodehydra- 
Table 4. Dielectric Constant and Bulk Density of the Polyimides and Polyamides

Thickness
$(\mu \mathrm{m})$ $\begin{gathered}\begin{array}{c}\text { Dielectric } \\ \text { constant } \\ (\text { Dry })\end{array} \\ \text { Density }\left(\mathrm{g} / \mathrm{cm}^{3}\right)^{a}\end{gathered}$

\footnotetext{
${ }^{a}$ The bulk density was measured by the method of Archimedes' principle, $\rho_{\text {bulk }}=A /(A-B) \times \rho_{\mathrm{w}}$, where $A$ is the dry membrane weight in air, $B$ is the membrane weight in water, and $\rho_{\mathrm{w}}$ is the water density. ${ }^{32}$
}

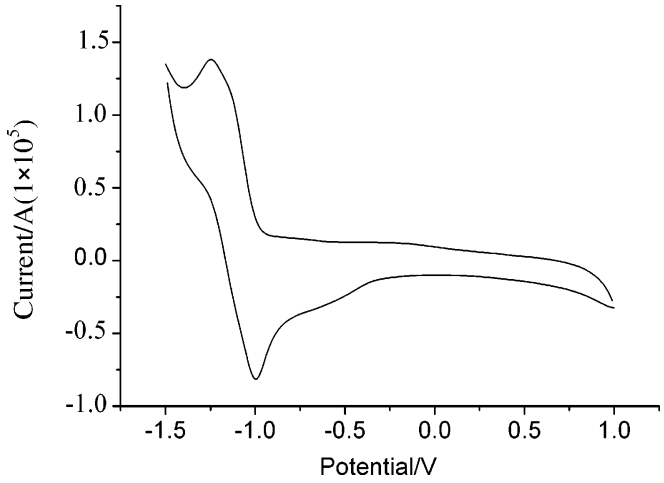

Figure 4. Cyclic voltammogram of polymer PI-1 in DMF with $\mathrm{Bu}_{4} \mathrm{NClO}_{4}(0.1 \mathrm{M})$ as the supporting electrolyte. Electrochemical oxidation and reduction behavior were measured by the $\mathrm{CV}$ method $(0-1.5 \mathrm{~V}, 100 \mathrm{mV} / \mathrm{s})$ in $\mathrm{DMF}$ using $\mathrm{Bu}_{4} \mathrm{NClO}_{4}(0.1$ $\mathrm{M})$ as the supporting electrolyte. The signals were obtained on a platinum working electrode, with a $\mathrm{Pt}$ wire as the counter electrode and a $\mathrm{Ag} / \mathrm{AgCl}$ (saturated) electrode as the reference electrode.

tion exhibited the highest tensile strength and tensile modulus. The polymer films were strong and hard.

Cyclic voltammetry is a convenient method to determine the electrochemical stability of organic materials (Figure 4.). Polymer solutions of PA-2 and PI-1 were prepared in DMF using $\mathrm{Bu}_{4} \mathrm{NClO}_{4}(0.1 \mathrm{M})$ as the supporting electrolyte. PA-2 was found to be stable toward both electrochemical oxidation and reduction. However, PI-1 shows a reversible reduction wave with $E_{1 / 2}$ at $1.12 \mathrm{~V}$ (Figure 4 ). We tentatively attributed this to the electron-withdrawing of the imide groups. On the other hand, unlike the diamine precursor, PI-1 and PA-2 are stable toward electrochemical oxidation. These results indicated that all the diamine precursors had been completely consumed in the reaction of condensation polymerization. No free amine was observed according to the $\mathrm{CV}$ analysis.

Typical examples of the electrical insulating properties of polymers in comparison with the naphthalene and methyl group on the 2,2'-position of biphenylene moiety had been evaluated on the basis of dielectric constant values (Table 4). In general, the $\pi$-conjugation of benzene structure increased the polarizability of a molecule. ${ }^{33}$ Interestingly, the dielectric constants of polyimde or polyamide containing naphthalene group are lower than methyl substitution. The bulky structures of the naphthalene group increase the free volume of polymer and further decrease the number of polarizable groups per unit volume, resulting in lower values for dielectric constant of atomic and dipolar. ${ }^{33,34}$

\section{Conclusion}

A series of new noncoplanar polyimides and polyamides based on biphenyldiamine containing a naphthalene group were successfully prepared by the polycondensation method with various tetracarboxylic dianhydrides and aromatic dicarboxylic acids. The introduction of a naphthalene group into the polymer backbone resulted in polyimides and polyamides with excellent solubility and mechanical properties. These polymers exhibited the characteristic of thermal stability by the naphthalene group and reduce the glass transition temperature of the rigid-rod-like structure which 
could improve the processing characteristics. These properties can make these polyimides and polyamides attractive for practical applications such as processable high-temperature engineering plastics because of the bulky and noncoplanar naphthalene groups in the polymer chain.

Acknowledgment. The authors thank the National Science Council of the Republic of China for their financial support.

\section{References and Notes}

(1) Ghosh, M. K.; Mittal, K. L. Polyimides: Fundamentals and Applications; Marcel Dekker: New York, 1996.

(2) Liaw, D. J.; Chen, W. H.; Huang, C. C. In Polyimides and Other High-Temperature Polymers; Mittal, K. L., Ed.; VSP Publisher: 2003; Vol. 2; pp 47-70.

(3) Liaw, D. J. In Macromolecular Nanostructured Materials; Ueyama, N., Harada, A., Kodansha, Springer, Eds.; 2004; Chapter 2.2, pp 80-100.

(4) Cassidy, P. E. Thermally Stable Polymer; Dekker: New York, 1980; Chapter 4.

(5) Hatke, W.; Schmidt, H. W.; Heitz, W. J. Polym. Sci., Polym. Chem. Ed. 1991, 29, 1387.

(6) Spiliopoulos, I. K.; Mikroyannidis, J. A. Macromolecules 1998, 31, 522 .

(7) Gaudiana, R. A.; Minns, R. A.; Sinta, R.; Weeks, N.; Rogers, H. G. Prog. Polym. Sci. 1989, 14, 47.

(8) Liaw, D. J.; Liaw, B. Y. Macromol. Symp. 1997, 122, 343.

(9) Liaw, D. J.; Hsu, P. N.; Chen, W. H.; Lin, S. L. Macromolecules 2002, 35, 4669.

(10) Liaw, D. J.; Liaw, B. Y.; Li, L. J.; Sillion, B.; Mercier, R.; Thiria, R.; Sekiguchi, H. Chem. Mater. 1998, 10, 734.

(11) Jeong, H. J.; Oishi, Y. M.; Kakimoto, A.; Imai, Y. J. Polym. Sci., Part A: Polym. Chem. 1990, 28, 3193.

(12) Ballauff, M.; Schmidt, G. F. Macromol. Chem. Rapid Commun. 1987, 8, 93.

(13) Steuer, M.; Horth, M.; Ballauff, M. J. Polym. Sci., Part A: Polym. Chem. 1993, 31, 1609 .
(14) Cheng, L.; Jian, X. G. J. Appl. Polym. Sci. 2004, 92, 1516.

(15) Yamada, M.; Kusama, M.; Matsumoto, T.; Kurosaki, T. Macromolecules 1993, 26, 4962.

(16) Kusama, M.; Matsumoto, T.; Kurosaki, T. Macromolecules 1994, 27, 1117.

(17) Liaw, D. J.; Liaw, B. Y.; Hsu, P. N.; Hwang, C. Y. Chem. Mater. 2001, 13, 1811

(18) Liaw, D. J.; Liaw, B. Y.; Yang, C. M. Macromolecules 1999 $32,7248$.

(19) Liaw, D. J.; Liaw, B. Y. Macromol. Chem. Phys. 1998, 199, 1473.

(20) Glatz, F. P.; Mulhaupt, R. Polym. Bull. 1993, 31, 137.

(21) Li, F.; Fang, S.; Ge, J. J.; Honigfort, P. S.; Chen, J. C.; Harris, F. W.; Cheng, S. Z. D. Polymer 1999, 40, 4571.

(22) Li, F.; Ge, J. J.; Honigfort, P. S.; Fang, S.; Chen, J. C.; Harris, F. W.; Cheng, S. Z. D. Polymer 1999, 40, 4987.

(23) Kim, K. H.; Jang, S.; Harris, F. W. Macromolecules 2001, $34,8925$.

(24) Fang, J.; Guo X.; Harada, S.; Watari, T.; Tanaka, K.; Kita, H.; Okamoto, K. I. Macromolecules 2002, 35, 9022.

(25) Matsuura, T.; Ando, S.; Sasaki, S. In Fluoropolymers 2 Properties; Hougham, G., Cassidy, P. E., John, K., Davidson, T., Eds.; Kluwer Academic/Plenum: New York, 1999; pp $305-350$

(26) Han K.; Lee H. J.; Rhee, T. H. J. Appl. Polym. Sci. 1999, $74,107$.

(27) Liaw, D. J.; Liaw, B. Y.; Jeng, M. Q. Polymer 1998, 39, 1597.

(28) Liaw, D. J.; Liaw, B. Y.; Chen, J. R.; Yang, C. M. Macromolecules 1999, 32, 6860 .

(29) Dixon, W.; Harris, M. M.; Mazengo, R. Z. J. Chem. Soc. B 1971, 775 .

(30) Puts, R. D.; Sogah, D. Y. Macromolecules 1995, 28, 390.

(31) Banihashemi, A.; Marvel, C. S. J. Polym. Sci., Polym. Chem. Ed. 1977, 15, 2653.

(32) Fan, S. C.; Wang, Y. C.; Li, C. L.; Lee, K. R.; Liaw, D. J.; Lai, J. Y. J. Appl. Polym. Sci. 2003, 88, 268.

(33) Tsuchiya, K.; Ishii, H.; Shibasaki, Y.; Ando, S.; Ueda, M. Macromolecules 2004, 37, 4794.

(34) Simpson, J. O.; St. Clair, A. K. Thin Solid Films 1997, 308 309,480 .

\section{MA048559X}

